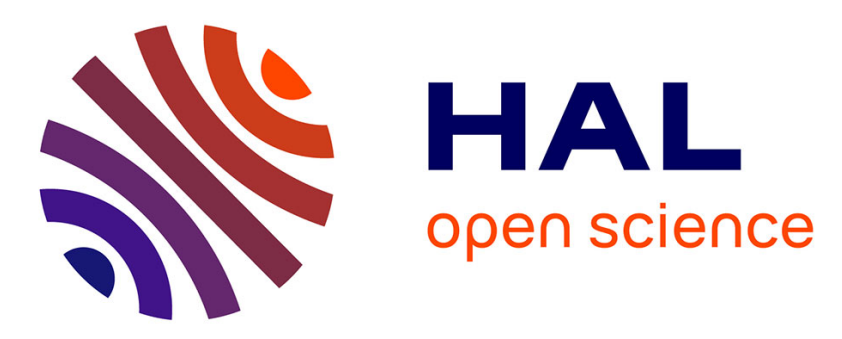

\title{
The FANTASIO+ set-up to investigate jet-cooled molecules: Focus on overtone bands of the acetylene dimer.
}

Keevin Didriche, Clement Lauzin, Tomas Foldes, Xavier de Ghellinck d'Elseghem Vaernewijck, Michel Herman

\section{To cite this version:}

Keevin Didriche, Clement Lauzin, Tomas Foldes, Xavier de Ghellinck d'Elseghem Vaernewijck, Michel Herman. The FANTASIO+ set-up to investigate jet-cooled molecules: Focus on overtone bands of the acetylene dimer.. Molecular Physics, 2010, pp.1. 10.1080/00268976.2010.489525 . hal-00598574

\section{HAL Id: hal-00598574 https://hal.science/hal-00598574}

Submitted on 7 Jun 2011

HAL is a multi-disciplinary open access archive for the deposit and dissemination of scientific research documents, whether they are published or not. The documents may come from teaching and research institutions in France or abroad, or from public or private research centers.
L'archive ouverte pluridisciplinaire HAL, est destinée au dépôt et à la diffusion de documents scientifiques de niveau recherche, publiés ou non, émanant des établissements d'enseignement et de recherche français ou étrangers, des laboratoires publics ou privés. 


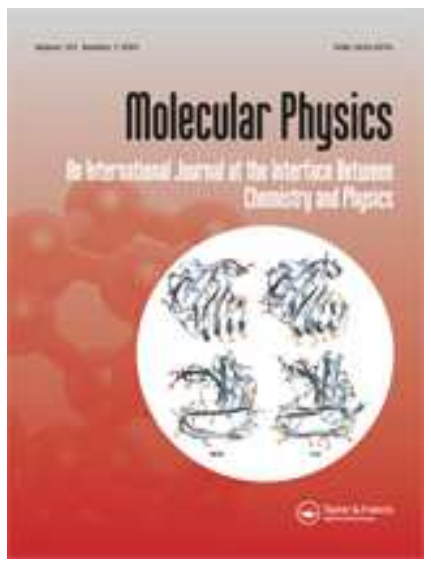

\section{The FANTASIO+ set-up to investigate jet-cooled molecules: Focus on overtone bands of the acetylene dimer.}

\begin{tabular}{|c|c|}
\hline Journal: & Molecular Physics \\
\hline Manuscript ID: & TMPH-2010-0115 \\
\hline Manuscript Type: & Special Issue Paper - Solvay workshop \\
\hline $\begin{array}{r}\text { Date Submitted by the } \\
\text { Author: }\end{array}$ & 02-Apr-2010 \\
\hline Complete List of Authors: & $\begin{array}{l}\text { Didriche, Keevin; Université Libre de Bruxelles, Chimie quantique et } \\
\text { Photophysique } \\
\text { LAUZIN, Clement; Université Libre de Bruxelles, Chimie quantique } \\
\text { et Photophysique } \\
\text { FOLDES, Tomas; Université Libre de Bruxelles, Chimie quantique et } \\
\text { Photophysique } \\
\text { de Ghellinck D'Elseghem Vaernewijck, Xavier; Université Libre de } \\
\text { Bruxelles, Chimie quantique et Photophysique } \\
\text { Herman, Michel; Université Libre de Bruxelles, Chimie quantique et } \\
\text { Photophysique }\end{array}$ \\
\hline Keywords: & $\begin{array}{l}\text { van der Waals complexe, acetylene dimer, acetylene-argon dimer, } \\
\text { CW-CRDS, overtone spectra in molecular complexes }\end{array}$ \\
\hline
\end{tabular}

\section{(5) ScholaroNE \\ Manuscript Central}




\title{
The FANTASIO+ set-up to investigate jet-cooled molecules: Focus on overtone bands of the acetylene dimer.
}

\author{
K. Didriche ${ }^{a}$, C. Lauzin, T. Földes ${ }^{b}$, X. de Ghellinck D'Elseghem Vaernewijck ${ }^{c}$, \\ and M. Herman.
}

Laboratoire de Chimie quantique et Photophysique

Faculté des Sciences

CP160/09

Université libre de Bruxelles

Ave. Roosevelt, 50

B-1050

Brussels, Belgium

${ }^{a}$ Postdoctoral Researcher (F.R.S.-FNRS)

${ }^{\mathrm{b}} \mathrm{ARC}$ postdoctoral researcher

${ }^{\mathrm{c}}$ FRIA Researcher

Pages: 30

Figures: 6

Tables: 2

Send mail to M. Herman

Email: mherman@ulb.ac.be 


\begin{abstract}
The experimental set-up FANTASIO, for "Fourier trANsform, Tunable diode and quadrupole mAss spectrometers interfaced to a Supersonic expansIOn" (M. Herman, K. Didriche, D. Hurtmans, B. Kizil, P. Macko, A. Rizopoulos, and P. Van Poucke, Mol. Phys. 105, 815 (2007)) built in Brussels has been updated. The turbomolecular pumping system of the supersonic expansion has been doubled and new mirrors, with reflectivity $99.999 \%$ instead of $99.99 \%$, have been set in the CW-cavity ring down spectrometer (CW-CRDS) probing jet-cooled molecules. The changes all together result in a signal to noise increased by up to a factor 10 , around $1.5 \mu \mathrm{m}$. These improvements are demonstrated with various acetylene data in the $2 \mathrm{CH}$ excitation range, including the assignment of a new sub-band of acetylene-Ar, with $\mathrm{K}^{\prime}-\mathrm{K}^{\prime \prime}=2-3$. The focus is set on the acetylene dimer. Overtone sub-bands, with $b$ - and $a$-type structures, are identified for the first time in the literature. The former are assigned to vibrational excitation in the hat unit of the T-shaped dimer, the latter, tentatively, to vibrational excitation in both units. The relevance of the overtone data on acetylene dimers for space remote sensing is highlighted.
\end{abstract}




\section{Introduction}

A vast experimental and theoretical literature was published mainly in the 90's about acetylene multimers (see e.g. ${ }^{2} 2345678910111213141511161718192021222324252627$

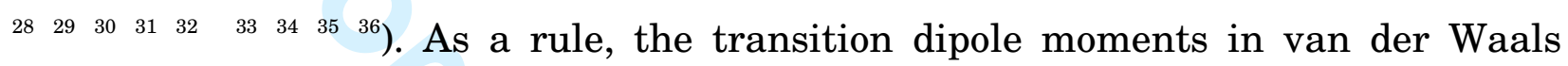
complexes mainly arise from the monomer units and the bands in the complexes usually lie very close to strong monomer bands. Acetylene multimers were reported around two infrared bands in the monomer: $v_{5}$, the cis-bending at $730 \mathrm{~cm}^{-1}$ and $v_{3}$, the $\mathrm{CH}$ asymmetric stretch at $3300 \mathrm{~cm}^{-1}$. Overtone bands in pure acetylene multimers were so far not reported. Following a preliminary low resolution report for acetylene- $\mathrm{Ar}^{37}$, overtone bands in mixed dimers containing acetylene were recently detected in a supersonic expansion, under sub Doppler conditions. These dimers are of acetylene with $\mathrm{Ar}^{38}, \mathrm{CO}_{2}^{39}$ and $\mathrm{N}_{2} \mathrm{O}^{40}$. The related acetylene monomer transition is $v_{1}+v_{3}$ (with $v_{1}$ the symmetric $\mathrm{CH}$ stretch), with origin at $6556.46 \mathrm{~cm}^{-1} 4142$. It will be further referred to here as $2 \mathrm{CH}$ excitation. These experiments were performed in Brussels using the FANTASIO set-up (for "Fourier trANsform, Tunable diode and quadrupole mAss spectrometers interfaced to a Supersonic expansIOn"). CW-cavity ring down spectroscopy (CW-CRDS) ${ }^{43} 44$ was the detection technique. 
While recording acetylene-Ar, other, larger absorption features were observed in the spectra. Contrary to all three assigned acetylene-Ar sub-bands in the range investigated which show resolved structure ${ }^{38}$, only few of these absorption features showed separate lines or clumps of lines. One of them was tentatively attributed to the pure acetylene dimer ${ }^{46}$. Other broader spectral features have not been reported in the literature, yet. Further evidence was brought for the formation of acetylene multimers in the expansion from very specific monomer line profiles. Indeed a central dip appears in the acetylene monomer line profile when using axisymmetric nozzles. These dips were observed in both acetylene-Ar and pure acetylene expansions. They were attributed to the decrease in monomer absorption due to condensation in the central part of the conical expansion, among other reasons ${ }^{46} 47$.

We have since modified FANTASIO. The pumping efficiency has been improved and higher performance mirrors have been installed in the CW-CRDS spectrometer. These changes are presented and illustrated in section II. The resulting set-up, named FANTASIO+ has been used to record new spectra using acetylene seeded in various rare gas expansions. The experimental results presented in section III are exploited to assign the carriers of the broad spectral features to acetylene multimers. These are identified and the bands are assigned in section IV. The results are discussed and put in the perspective of remote sensing in section $\mathrm{V}$, before concluding. 


\section{FANTASIO+}

FANTASIO was described previously in the literature ${ }^{48}$. Relevant to the present investigation are the CW-CRDS spectrometer and the supersonic expansion. Only their main features are recalled in this section, and the changes highlighted. The reader should note that the detailed experimental conditions for the spectra that will be presented are indicated in the figure captions and not detailed in the text. Acetylene was from Air Liquide (99.6 \% purity) and used without further purification. The many strong lines from the monomer $\left({ }^{12} \mathrm{C}_{2} \mathrm{H}_{2}\right.$ or $\left.{ }^{12} \mathrm{CH}^{13} \mathrm{CH}\right)$ appearing on the spectra are not identified in the Figures.

\section{A. Supersonic expansion}

In the new set-up, named FANTASIO+, the free supersonic jet expansion is produced using two identical, large turbomolecular pumps (Leybold MAG W3200 CT; 3200 l/s). They are teflon coated and backed by an Alcatel ADS 860 HII group. The previous system had only one of these, with the same primary pumps. Both turbomolecular units are directly mounted below the cylindrical expansion cell, about $32 \mathrm{~cm}$ in diameter. The $\mathrm{Y}$ connection matches the identical pump and cell diameters. The reservoir $\left(\mathrm{p}_{0}\right)$ and residual $\left(\mathrm{p}_{\infty}\right)$ pressures are measured using MKS Baratron gauges (1000 and 1 torr full scale, respectively). The acetylene and carrier gas flows are measured using MKS and Brooks flowmeters (10000 and $50000 \mathrm{sccm}$ 
full scale, respectively -SCCM denotes cubic centimeter per minute at STP). The reservoir pressure is now typically $100 \mathrm{kPa}$, as opposed to $50 \mathrm{kPa}$ before, for similar residual pressures, of the order of $1 \mathrm{~Pa}$. Thanks to the increased pressure ratio and flow rates, the signal to noise ratio $(\mathrm{S} / \mathrm{N})$ is boosted. This is illustrated in Figure 1. Spectra of $\mathrm{C}_{2} \mathrm{H}_{2}$-Ar recorded with one and two turbomolecular pumping units are shown in panels (1) and (2), respectively. The comparison demonstrates an increase of a factor 2 in the $\mathrm{S} / \mathrm{N}$. As another consequence, $\mathrm{He}$ and Ne could be used as carrier gases, in addition to Ar, while overriding the pump capacity before. A wider range of experimental degrees of freedom is thus made available. This will be exploited in section III.

\section{B. CW-CRDS spectrometer}

The general features of the CW-CRDS spectrometer, directly inspired by the developments from Romanini and coworkers ${ }^{49}{ }^{50}$, are unchanged in FANTASIO+. DFB tunable diode lasers (TDL) emitting in the $1.5 \mu \mathrm{m}$ range (e.g. ILX lightwave, 1 $\mathrm{MHz}$ linewidth) are used. The TDL beam is sent through an optical isolator (Thorlabs 4015 5AFC-APC) and then split by a coupler (Thorlabs, 10 202A-99-APC). Some $1 \%$ of the light intensity is sent via a fiber collimation package $(\mathrm{f}=8 \mathrm{~mm}$ ) into a home-made Fabry-Pérot interferometer made of two 50\% reflectivity flat mirrors positioned on an Invar bar. This etalon provides a FSR of about $955 \mathrm{MHz}$. The remaining $99 \%$ of the light is focused by a fiber collimation package $(\mathrm{f}=4.5 \mathrm{~mm})$ onto 
an acousto-optical modulator (AOM) from AA Opto-Electronic (MGAS 80-A1). The first order diffraction from the $\mathrm{AOM}$ is injected into the $\mathrm{TEM}_{00}$ mode of a linear ringdown cavity through two lenses $\left(f_{1}=30 \mathrm{~mm}, f_{2}=50 \mathrm{~mm}\right)$ and two steering mirrors. The cavity is composed of two concave mirrors (Radius $=1000 \mathrm{~mm}$ ), separated by about $540 \mathrm{~mm}$. The output mirror is mounted on a piezo actuator (Piezomechanik HPST $1000 / 15-8 / 5)$. The light exiting the cavity is focused through a lens $(\mathrm{f}=20 \mathrm{~mm})$ on a photodiode. The light detection system from FANTASIO was modified and is described later in this section.

For ring-down detection, the piezo actuator is driven at a selected frequency (typically $500 \mathrm{~Hz}$ ) and cavity mode matching with the laser is achieved at twice the selected frequency. The AOM is switched off as soon as the cavity mode intensity attains a threshold value. The same event triggers the measurement procedure of the ring-down decay. This procedure is controlled by the same home-made electronics as before. The ring-down decays are sampled by a PCI-6251 multifunction data acquisition card, with $16 \mathrm{bit} 1.25 \mathrm{MHz}$ analog-to-digital converter. The acquisition is PC driven by home-made software written using LabVIEW. Each ring-down exponential decay is fitted by a procedure based on the nonlinear Levenberg-Marquardt method. The absorption coefficient $\alpha$ is directly calculated using ${ }^{44}$ : 


$$
\alpha=\left(v-v_{0}\right) \frac{L}{c l}
$$

in which $v_{0}$ is the ring-down decay frequency in an empty cavity (i.e. without absorber), $L$ and $l$ are respectively the lengths of the cavity and the absorption path in the medium and $c$ is the speed of light. The TDL frequency can be continuously tuned by sweeping the temperature using a home-made PID stabilizer. The temperature tuning from about $60{ }^{\circ} \mathrm{C}$ to $-5{ }^{\circ} \mathrm{C}$ corresponds approximately to the 6534 to $6570 \mathrm{~cm}^{-1}$ spectral range when using the diode mentioned earlier.

The most significant difference from FANTASIO is the typical ring-down time. It was between 15 and $20 \mu \mathrm{s}$ in our previous experiments. It has been increased to some $120 \mu \mathrm{s}$, using a new set of mirrors (Layertec). Their measured reflectivity is $\mathrm{R}=99.9985 \%$. The number of passes has been extended from about 8300 , previously, to 66000 now. When using a slit $1 \mathrm{~cm}$ long (and $30 \mu \mathrm{m}$ wide), as in the present version of FANTASIO+, the effective absorption path in the cooled gas is $660 \mathrm{~m}$.

As an effect of the very high reflectivity of the new cavity mirrors the typical light power leaking out of the cavity has significantly decreased. A new detection system comprising a Hamamatsu InGaAs PIN photodiode (G8376-03) connected in photoconductive mode with a three-stage readout circuit is employed to record ringdown transients reliably. In the readout circuit a JFET-input stage operational amplifier (OPA657) connected as a wideband transimpedance amplifier is used. The second stage amplifier (OPA843) provides additional adjustable gain and offset. A 


\begin{abstract}
fully-differential amplifier (THS4503) for single-ended to differential conversion drives the analog-to-digital converter. Low-pass filtering is set so that $1 \mu \mathrm{s}$ smallsignal pulses can be satisfactorily resolved. Careful attention has been given to circuit-board layout to minimize leakage current and parasitics.
\end{abstract}

As an illustration of the results, the spectrum in panel (3) in Figure 1 was recorded using the updated spectrometer, in addition to the two pumps used for panel (2). Spectra in Figure 1 were recorded at different stages of the development of the set-up. The slit length and therefore the flow rates, in particular, were modified. Accounting for these variations, the $\mathrm{S} / \mathrm{N}$ is improved by a factor of about 5 between panels (2) and (3). The intensity scale was multiplied by the required factor (1.5) in panel (3), to achieve comparable visual noise level to panel (2). The gain from the pump doubling, demonstrated from panel (1) to (2), was about 2 . The overall gain in S/N between FANTASIO and FANTASIO+, comparing regular operational conditions, is thus about 10 . The present $\alpha_{\min }$, approximated as $\mathrm{S} / \mathrm{N}=2 / 1$ and calculated for $1 \mathrm{~cm}$ absorption path under the slit nozzle, is calculated to be $3.1810^{-8}$ $\mathrm{cm}^{-1}$. This significant improvement will be fully exploited when getting to the detailed rotational analysis of the spectral features. This step is, however not achieved in this investigation, yet.

\title{
III. Experimental results
}


The spectral range of interest to the present investigation is from 6534 to $6565 \mathrm{~cm}^{-1}$. Thanks to the increased pumping capacity, acetylene spectra could be recorded using various carrier gases and nozzle geometries. This is illustrated in Figure 2. The spectrum in the middle panel was recorded with Ar and a slit nozzle. The one in the top panel was recorded using $\mathrm{Ne}$ and an axisymmetric nozzle. As pointed out in the previous section, the use of $\mathrm{Ne}$ was previously limited by the single pump capacity. Despite the double pumping scheme, a circular nozzle of reduced diameter (150 microns) had still to be used when recording the spectrum with Ne. The comparison in Figure 2 demonstrates that numerous spectral features are observed independently of the carrier gas. They can therefore reliably be assigned to acetylene multimers. Their appearance may actually vary from one carrier gas and nozzle type to another because of different cooling conditions. These bands, listed in Table 1, thus provide definite evidence for the existence of pure acetylene weakly bound molecular complexes in the overtone spectral range.

Multimer production using FANTASIO+ appears to be optimal when using Ar as a carrier gas, compared to $\mathrm{Ne}$ and He. Unfortunately, acetylene-Ar bands are also strong and new sub-bands compared to our previous report ${ }^{38}$ are observed on the spectra recorded using FANTASIO+. They are often overlapped with multimer bands creating severe identification problems whenever focusing on more structured spectral features, in particular.

We attempted to discriminate the molecular carrier of the bands by varying the experimental conditions. The related spectra were actually recorded using the 
two pumping units before the new CW-CRDS system was installed. They nevertheless provide the relevant information and are used in this section. A spectral range showing only previously unidentified absorption features is selected in Figure 3. The amount of carrier gas (Ar) was kept constant while changing the flow of acetylene by up to a factor 3, from bottom to top in this Figure. For some of the features, including most of the well resolved lines, the intensity decreases when adding acetylene. This response to experimental changes is found to characterize all known acetylene-Ar sub-bands. This is illustrated with the known $K^{\prime}-K^{\prime \prime}=2-1$ subband $^{38}$ in Figure 4, which shows another section of the same three sets of spectra presented in Figure 3. Most of the resolved features in Figure 3 are thus from acetylene-Ar. They turn out to be the $K^{\prime}-K^{\prime \prime}=2-3$ sub-band, not previously reported, with the $P$ branch forming the band head at $6548.417 \mathrm{~cm}^{-1}$ and the $Q$ branch starting at $6548.792 \mathrm{~cm}^{-1}$. The upper $\mathrm{K}^{\prime}=2$ sub-state was already observed through the 2-1 sub-band and found to be perturbed ${ }^{38}$. Band simulations not further detailed here demonstrate that the lower $K "=3$ sub-state, not previously reported, is also perturbed as could be predicted from literature results concerning $\mathrm{K}^{\prime \prime}=2{ }^{51}$. A more detailed analysis of the acetylene-Ar sub-bands revealed by FANTASIO+ is under way and not further detailed in this report.

The trend when varying pressure conditions is different for other spectral features such as the broad absorption at $6546.5 \mathrm{~cm}^{-1}$ appearing in Figure 3 . The band intensity indeed increases when doubling the acetylene flow rate. We checked that this other behavior characterizes all bands listed in Table 1 that could 
be assigned to acetylene multimers. It is interesting to notice that the growing of the multimer bands with increasing acetylene flow rate stops when tripling the acetylene concentration, as shown in the top panel of Figure 3. This trend probably corresponds to the decrease in cooling efficiency and therefore in multimer production. The final experimental conditions were accordingly adapted and fine tuned, depending if investigating acetylene-Ar or acetylene multimers.

The present comparison provides more detailed insight than the one between $\mathrm{Ne}$ and Ar carrier gases in Figure 2. It can e.g. be checked that weaker resolved lines and unresolved clumps appearing in the middle of the acetylene-Ar sub-band in Figure 3 between 6548.4 and $6549.0 \mathrm{~cm}^{-1}$, are behaving similarly as the broad feature at $6546.5 \mathrm{~cm}^{-1}$. Their carrier is thus identified to an acetylene multimer.

\section{IV.Assignment of multimer bands}

We focus now on the multimer spectral features. We attempted various simulations using literature constants for the dimer ${ }^{52}$, trimer $^{9}{ }^{14}$ and tetramer ${ }^{14}$. Colin Western's PGOPHER program ${ }^{53}$ was used. Although reasonable match could be achieved for specific bands with the larger aggregates constants, none agreed as well as the one presented in Figure 2, at the bottom. This simulation uses $b$-type selection rules, involving an upper state of $\mathrm{B}_{2}$ symmetry, for a rigid T-shaped structure in a $\mathrm{C}_{2 \mathrm{v}}$ group symmetry. The comparison definitely identifies the pure 
acetylene dimer as the carrier. The match is impressive, accounting for almost all sub-bands assigned to multimers. These are identified using the conventional ${ }^{\Delta K} \Delta J_{K^{\prime \prime}}\left(J^{\prime \prime}\right)$ notation in both Figure 2 and Table 1 . We did not include tunneling effects $^{11}$ in the simulation. We only accounted for the 1:3 intensity alternation expected for a rigid-type molecule. Previous investigation of mixed acetylene dimers, with $\mathrm{CO}_{2}^{39}, \mathrm{~N}_{2} \mathrm{O}^{40}$ and $\mathrm{Ar}^{38}$, demonstrated extensive perturbations in this $2 \mathrm{CH}$ excitation range. They are further confirmed with the $K^{\prime}-K^{\prime \prime}=2-3$ sub-band in acetylene-Ar briefly discussed in the previous section. For the pure dimer, one can check in Figure 2 that several of the sub-band origins are not properly reproduced. More detailed comparisons confirm the existence of perturbations compared to rigidasymmetric top-type predictions. The detailed analysis of the overtone pure acetylene dimer bands will require a dedicated investigation. The constants used for the simulation, listed in Table 2, are thus approximate and preliminary. Those of the ground state in this Table correspond to the mean value of the three sets published in their Table VI by Fraser and coworkers ${ }^{11}$. Only the most influent parameters on the band contour simulation were considered. The upper state constants were adjusted empirically for optimal match with the various broader dimer structures.

One additional broader feature is apparent in Figure 2, with prominent $Q$ and $R$ branches around 6538.3 and $6539.5 \mathrm{~cm}^{-1}$, respectively. It is not accounted for in the simulation of the dimer structure just discussed. We first checked that $v_{1}+v_{3}$ was the only band in the monomer in the range investigated. We then attempted 
simulations of the observed band contour using rotational constants based on ground state rotational constants. We again started with trimer and the tetramer literature constants. Reasonable match could be achieved in both cases. But, again, the comparison with the dimer was strikingly convincing. It is presented in Figure 5 (top). This time, however, $a$-type selection rules are required in the simulation, involving an upper state of $\mathrm{A}_{1}$ symmetry. The upper state constants obtained similarly as for the $b$-type band are listed in Table 2 . To optimize the comparison, $a$ and $b$-type structures contributing to the spectral features in the range covered in Figure 5 were overlapped (middle). The $b$-type ${ }^{p} Q_{3}(J)$ sub-band, already mentioned to be perturbed, were red-shifted by $0.34 \mathrm{~cm}^{-1}$ in the simulation to improve the agreement. The same shift was applied to the weaker ${ }^{p} Q_{4}(J)$ and ${ }^{p} Q_{5}(J)$ subbands. Only the ${ }^{p} Q_{3}(J)$ sub-band is visible among the $a$-type absorption feature.

\section{Discussion}

The dimer is known to be planar, T shaped ${ }^{10}{ }^{52}$, thus with perpendicular "hat" and "body" acetylene monomer units. We shall hereafter label these units 1 and 2 , respectively, as indicated in Figure 6. The $b$-type structure we have reported in the pure dimer, which was simulated in Figure 2, is typical of all acetylene mixed dimers $^{38}{ }^{39} 40$. The $2 \mathrm{CH}$ excitation $\left(v_{1}+v_{3}\right.$ in the monomer) is along the $b$-axis of inertia that is located in unit 1 for the pure dimer. 
The origin of the $a$-type band $\left(6538.3 \mathrm{~cm}^{-1}\right)$, which only occurs in the pure dimer, is red-shifted compared to the $b$-type one by about $8 \mathrm{~cm}^{-1}\left(6547.6 \mathrm{~cm}^{-1}\right)$. The same shift was found to occur in the $3 \mu \mathrm{m}, 1 \mathrm{CH}\left(v_{3}\right)$ band between the similar $a$ - and $b$-type excitation bands ${ }^{11}$. It is likely to be due for both $1 \mathrm{CH}$ and $2 \mathrm{CH}$ excitations to the encaged nature of the $\mathrm{C}-\mathrm{H}$ bond of unit 2 making the van der Waals bond with unit 1 (see Figure 6). The movement of this $\mathrm{CH}$ bond is restricted and the vibrational frequency is reduced. If correct, this statement should also apply to the other, symmetric $\mathrm{CH}$ vibration, i.e. $v_{1}$ in the monomer. Such a reduction in both $\mathrm{CH}$ fundamentals is predicted by $a b$ initio calculations ${ }^{10}$. So, if the $2 \mathrm{CH} a$-type excitation entirely occurred in unit 2, one should expect the $a$-type band origin to be red-shifted compared to the $b$-type one by roughly twice as much as for $v_{3}$ in the $1 \mathrm{CH}$ range, i.e. about $16 \mathrm{~cm}^{-1}$. Since shifts are almost identical, i.e. about $8 \mathrm{~cm}^{-1}$, it looks as if the $2 \mathrm{CH}$ excitation giving rise to the $a$-type band occurred in different acetylene units. The asymmetric $\mathrm{CH}$ excitation (similar to $v_{3}$ in the monomer) takes place in unit 2 ; it is responsible for the band strength and selection rules. The symmetric excitation (similar to $v_{1}$ in the monomer) occurs in unit 1 ; it presents the same frequency parameters as in the other, $b$-type excitation. This explanation, however, does not account for any possible change in $x_{13}$, the mixed anharmonicity parameter. Nor does it account for any modification in the strength of anharmonic resonances in monomer and dimer structures, also responsible for the values of the band origins. Unfortunately, the rotational constants listed in Table 2 are not very helpful in this problem. As for $v_{3}{ }^{11}$, indeed, the asymmetric top rigid-type Hamiltonian we have 
used is not adequate and the upper state rotational constants cannot be reliably compared. The present assignment in terms of mixed excitation in the two acetylene units is only based on the shift of the vibrational band origins. It remains tentative. If ever confirmed, it would probably be the first such case to be reported, for any van der Waals dimer.

The present results account for the multimer bands revealed thanks to the increased performances of FANTASIO+. Aggregates larger than the dimer seem therefore not to be observed on the spectra we have recorded. Much larger pressure ratios $\mathrm{p}_{0} / \mathrm{p}$. were usually associated to their observation in the lower IR region in the literature, usually with $\mathrm{He}$ as carrier gas and sometimes with pulsed injection systems. Nevertheless, we were able to observe larger multimers with the previous FANTASIO set-up around $3 \mu \mathrm{m}$ using $\mathrm{Ar}^{35}$, thus before adding the second turbomolecular pump. Their absence could therefore indicate their fast predissociation in the presently investigated, $2 \mathrm{CH}$ excitation range. This is thus not the case with dimers.

The optimal temperature for the simulations was found to be $\mathrm{T}_{\mathrm{rot}}=20 \mathrm{~K}$. Lines from all relevant $J / K$ states were included in the simulation. We convolved the Doppler line profile for $\mathrm{T}_{\text {rot }}=20 \mathrm{~K}$ with a Lorentzian profile. The optimal FWHM was found to be 0.015 and $0.075 \mathrm{~cm}^{-1}$ for $b$ - and $a$-type transitions, respectively. These values are much larger than for acetylene-Ar in the same range. In this mixed dimer, the widths for unperturbed lines were determined to be $710^{-4} \mathrm{~cm}^{-1} \mathrm{FWHM}$, corresponding to a mean half-time of $7.5 \mathrm{~ns}^{38}$. The wider profiles in the pure dimer 
indicate a much smaller lifetime. It is even five times shorter in the $\mathrm{A}_{1}$ upper state, corresponding to vibrational excitation in unit 2 , than in the $\mathrm{B}_{2}$ state involving unit 1 excitation. However, the present values result from the analysis of band contours with strong line overlap. They need to be confirmed from a detailed line analysis. In any case, the present results demonstrate that this problem does not prevent the pure dimer species to be monitored and detected in situ, around $1.5 \mu \mathrm{m}$.

Acetylene is observed in numerous outer environments such as $\operatorname{comets}^{5455}$, planetary ${ }^{57} 58$ (including $\operatorname{Earth}^{59}{ }^{60}$ and $\operatorname{Titan}^{61}$ ) and stellar ${ }^{62} 63$ atmospheres, and the interstellar medium ${ }^{65} \quad \begin{array}{llll}66 & 67 & 68 & 69\end{array}$. Some of the laboratory experiments ${ }^{6}{ }^{20}$ report the observation of acetylene dimers under temperature conditions are not that different from those on Titan for instance. Furthermore, pressure conditions in some outer environments such as Titan are in favor of the formation of aggregates, as specifically investigated in ${ }^{20}$. It is therefore not unlikely that acetylene dimers be formed in space.

Portable spectrometers are nowadays becoming available in the NIR spectral range $^{70}{ }^{71}$, often providing significantly increased sensitivity compared to mid IR remote sensors. The telecom DFB diode laser spectral range, around $1.6 \mu \mathrm{m}$, as presently used, is of specific relevance for space detection. These lasers are fibered, portable and can indeed be associated to ultra high sensitivity techniques as the one used in the present investigation. This increased detection sensitivity, compared to typical FTIR sensors compensates for the smaller band strength of overtone and combination bands in the NIR region, compared to fundamental bands in the lower 
IR. In addition, thanks to increased contribution of anharmoncity parameters, the stronger overtone vibrational bands, involving multiple $\mathrm{CH}$ excitation for instance, are usually more separated from one species to another in the overtone range, thus decreasing overlapping problems and making the band search easier. Finally, we have now demonstrated that pure acetylene dimers can be observed and spectroscopically characterized at high vibrational excitation energies, around $2 \mathrm{CH}$ stretches. The NIR region therefore provides an appealing alternative for remote sensing of the pure acetylene dimers in space.

\section{VI.Conclusion}

The FANTASIO set-up developed in Brussels was modified by including a second turbomolecular unit to produce the expansion. As a result, carrier gases other than Ar could be used, with also more flexibility in the nozzle sizes and designs. The CW-CRDS spectrometer probing jet-cooled molecules was also updated by using a significantly more reflective set of mirrors in the cavity around the free jet. The performances of the resulting FANTASIO+ set-up were illustrated using various acetylene data. A newly reported sub-band in $2 \mathrm{CH},{ }^{12} \mathrm{C}_{2} \mathrm{H}_{2}-\mathrm{Ar}\left(\mathrm{K}^{\prime}-\mathrm{K} "=2-3\right)$ was presented. Sub-bands of the pure acetylene dimer could be assigned, again in the $2 \mathrm{CH}$ excitation range, to $b$ - and $a$-type transitions. The latter could possibly correspond to single $\mathrm{CH}$ excitation in each of the monomer units. 
This report thus definitely assesses the existence of pure acetylene dimers in the $2 \mathrm{CH}$, overtone spectral region. It opens up room for more detailed spectroscopic investigation for both pure and mixed acetylene dimers, and probably of other species relevant for space remote sensing.

\section{Acknowledgements}

We are indebted to Dr P. Macko (UK Bratislava) for indicating the commercial availability of the new mirror set we have used, to Dr W.J. Lafferty (NIST) for simulations on larger multimers and to Dr. Colin Western for making his PGOPHER program available. X. de Ghellinck thanks F.R.I.A. for a research grant. We are most indebted to B. Kizil, A. Rizopoulos and P. Van Poucke for their technical help. We thank the Fonds National de la Recherche Scientifique (F.R.S.FNRS, contracts FRFC and IISN), the Université libre de Bruxelles and the «Action de Recherches Concertées de la Communauté française de Belgique» for financial support. 


\section{Figure captions}

Figure 1: CW-CRDS jet-cooled spectrum of a mixture of ${ }^{12} \mathrm{C}_{2} \mathrm{H}_{2}$ and Ar around $6548.5 \mathrm{~cm}^{-1}$. The initial FANTASIO set-up was used for the spectrum presented in panel (1), then updated with a second turbomolecular pump in panel (2) then with the more reflective CRDS mirror set in panel (3). The intensity scale was multiplied by a factor 1.5 in panel (3) to reflect the gain in the $\mathrm{S} / \mathrm{N}$ level, compared to panel (2) (see text). The slit nozzle was $14 \mathrm{X}$ $0.03 \mathrm{~mm}$ (1); $30 \mathrm{X} 0.015 \mathrm{~mm}$ (2); and $10 \mathrm{X} 0.03 \mathrm{~mm}$ (3). The experimental conditions are $1 \%$ $\mathrm{C}_{2} \mathrm{H}_{2}$ in $99 \% \mathrm{Ar} ; \mathrm{p}_{0} / \mathrm{p}_{\infty}=81000 / 3.3 \mathrm{~Pa}(1) ; 151000 / 2.1 \mathrm{~Pa}(2)$; and 129000/1.6 Pa (3).

Figure 2: Absorption features recorded using FANTASIO+, with ${ }^{12} \mathrm{C}_{2} \mathrm{H}_{2}$ seeded in $\mathrm{Ne}$ (top) and Ar (middle) using adapted nozzle geometries. The spectrum of the pure acetylene dimer simulated using $b$-type selection rules is presented at the bottom (see text for further details). The central $Q$ branches are identified according to the usual notation ${ }^{\Delta K} \Delta J_{K^{\prime \prime}}\left(J^{\prime \prime}\right)$. Flow and pressure conditions: $\mathrm{C}_{2} \mathrm{H}_{2} / \mathrm{Ne} 184 / 1118 \mathrm{sccm} / \mathrm{min}, \mathrm{p}_{0} / \mathrm{p}_{\infty}=322000 / 0.5 \mathrm{~Pa}$, axisymmetric nozzle, $150 \mu \mathrm{m}$ diameter (top); $\mathrm{C}_{2} \mathrm{H}_{2} / \mathrm{Ar} 185 / 2929 \mathrm{sccm} / \mathrm{min}, \mathrm{p}_{0} / \mathrm{p}_{\infty}=126000 / 2.5$ $\mathrm{Pa}$, slit nozzle $10 \mathrm{X} 0.03 \mathrm{~mm}$ (middle). $\mathrm{T}_{\text {rot }}=20 \mathrm{~K}$ in the simulation.

Figure 3: Portion around $6548 \mathrm{~cm}^{-1}$ of the CW-CRDS jet-cooled spectrum of a mixture of ${ }^{12} \mathrm{C}_{2} \mathrm{H}_{2}$ and Ar recorded using the same injection flow rate of Ar and acetylene flow rates increasing in the ratio 1 (bottom), 2 (middle) and 3 (top). The initial FANTASIO spectrometer was used with, however two turbomolecular pumping units. The slit nozzle 
was $30 \mathrm{X} 0.015 \mathrm{~mm}$. Flow and pressure conditions: $\mathrm{C}_{2} \mathrm{H}_{2} / \mathrm{Ar} 98.4 / 4882 \mathrm{sccm} / \mathrm{min}, \mathrm{p}_{0} / \mathrm{p}_{\infty}=$ 146000/1.9 Pa (bottom); $\mathrm{C}_{2} \mathrm{H}_{2} / \mathrm{Ar} 196.8 / 4882 \mathrm{sccm} / \mathrm{min}, \mathrm{p}_{0} / \mathrm{p}_{\infty}=147000 / 1.6 \mathrm{~Pa}$ (middle); $\mathrm{C}_{2} \mathrm{H}_{2} / \mathrm{Ar} 290 / 4882 \mathrm{sccm} / \mathrm{min}, \mathrm{p}_{0} / \mathrm{p}_{\infty}=149000 / 1.9 \mathrm{~Pa}$ (top).

Figure 4: Portion around $6560 \mathrm{~cm}^{-1}$ of the CW-CRDS jet-cooled spectrum of a mixture of ${ }^{12} \mathrm{C}_{2} \mathrm{H}_{2}$ and Ar recorded using the same injection flow rate of $\mathrm{Ar}$ and acetylene flow rates increasing in the ratio 1 (bottom), 2 (middle) and 3 (top). The initial FANTASIO spectrometer was used with, however the two turbomolecular pumping units. The slit nozzle was $30 \mathrm{X} 0.015 \mathrm{~mm}$. Flow and pressure conditions: $\mathrm{C}_{2} \mathrm{H}_{2} / \mathrm{Ar} 98.4 / 4882 \mathrm{sccm} / \mathrm{min}, \mathrm{p}_{0} / \mathrm{p}_{\infty}=$ 146000/1.9 Pa (bottom); $\mathrm{C}_{2} \mathrm{H}_{2} / \mathrm{Ar} 196.8 / 4882 \mathrm{sccm} / \mathrm{min}, \mathrm{p}_{0} / \mathrm{p}_{\infty}=147000 / 1.6 \mathrm{~Pa}$ (middle); $\mathrm{C}_{2} \mathrm{H}_{2} / \mathrm{Ar} 290 / 4882 \mathrm{sccm} / \mathrm{min}, \mathrm{p}_{0} / \mathrm{p}_{\infty}=149000 / 1.9 \mathrm{~Pa}$ (top).

Figure 5: Bottom: CW-CRDS jet-cooled spectrum of a mixture of ${ }^{12} \mathrm{C}_{2} \mathrm{H}_{2}$ and Ar recorded using FANTASIO+. Top: Spectrum of the pure acetylene dimer simulated using $a$-type selection rules. Middle: Spectrum of the pure acetylene dimer simulated using $a$ - and also $b$-type selection rules; The $b$-type $\Delta K=-1$ sub-bands with $K "=3$ to 5 are included. The branches are identified according to the usual notation ${ }^{\Delta K} \Delta J_{K^{\prime \prime}}\left(J^{\prime \prime}\right)$. Flow and pressure conditions are identical to those of Figure 2 (mid panel). $\mathrm{T}_{\mathrm{rot}}=20 \mathrm{~K}$ in the simulations.

Figure 6: T-shaped structure of the pure acetylene dimer, with principal axes of inertia. 


\section{Table legends}

Table 1: Positions $\left(\mathrm{cm}^{-1}\right)$ of the acetylene dimer $Q$ branches observed in the $2 \mathrm{CH}$ spectral excitation range. The sub-bands are identified according to the usual notation ${ }^{\Delta K} \Delta J_{K^{\prime \prime}}\left(J^{\prime \prime}\right)$.

Table 2: Constants used to simulate spectral structures attributed to $\left({ }^{12} \mathrm{C}_{2} \mathrm{H}_{2}\right)_{2}$ in the NIR spectral range.

${ }^{a}$ adapted from Fraser et al. ${ }^{11}$ (see text). 


\section{References}

$1 \quad$ D. McIntosh, J. Phys. Chem. 11, 306 (1907).

2 D. F. Eggers, N. W. Gregory, G. D. Halsey, and B. S. Rabinovitch, Physical chemistry. (John Wiley and Sons, 1964).

K. Sakai, A. Kiode, and T. Kihara, Chem. Phys. Lett. 47, 416 (1977).

T. Aoyama, O. Matsuoka, and N. Nakagawa, Chem. Phys. Lett. 67, 508 (1979).

5 D. M. Hoffman, R. Hoffmann, and C. R. Fisel, J. Am. Chem. Soc. 104, 1858 (1982).

$6 \quad$ R. D. Pendley and G. E. Ewing, J. Chem. Phys. 78, 3531 (1983).

7 R. E. Miller, P. F. Vohralik, and R. O. Watts, J. Chem. Phys. 80, 5453 (1984).

$8 \quad$ G. Fischer, R. E. Miller, P. F. Vohralik, and R. O. Watts, J. Chem. Phys. 83, $1471(1985)$.

9 D. G. Prichard, J. S. Muenter, and B. J. Howard, Chem. Phys. Lett. 135, 9 (1987).

I. L. Alberts, T. W. Rowlands, and N. C. Handy, J. Chem. Phys. 88, 3811 (1988).

11 G. T. Fraser, R. D. Suenram, F. J. Lovas, A. S. Pine, J. T. Hougen, W. J. Lafferty, and J. S. Muenter, J. Chem. Phys. 89, 6028 (1988).

$12 \quad$ A. Weber, J. Chem. Phys. 88, 3428 (1988).

13 Y. Oshima, Y. Matsumoto, and M. Takami, Chem. Phys. Lett. 147, 1 (1988). 
G. W. Bryant, D. F. Eggers, and R. O. Watts, J. Chem. Soc. Faraday Trans. II 84, 1443 (1988).

D. G. Prichard, R. N. Nandi, and J. S. Muenter, J. Chem. Phys. 89, 115 (1988).

R. G. A. Bone, R. D. Amos, and N. C. Handy, Journal of the Chemical Society, Faraday Transactions 86, 1931 (1990).

J. Yu, S. Su, and J. E. Bloor, J. Chem. Phys. 94, 5589 (1990).

T. Dunder and R. E. Miller, J. Chem. Phys. 93, 3693 (1990).

K. Matsumura, F. J. Lovas, and R. D. Suenram, J. Mol. Spectrosc. 150, 576 (1991).

A. J. Colussi, S. P. Sander, and R. R. Friedl, Chem. Phys. Lett. 178, 497 (1991).

R. G. A. Bone, T. W. Rowlands, N. C. Handy, and A. J. Stone, Molecular “Physics 72, 33 (1991).

I. I. Suni and W. Klemperer, J. Chem. Phys. 98, 988 (1993).

J. D. Augspurger and C. E. Dykstra, Int. J. Quantum Chem. 43, 135 (1992).

R. L. Bhattacharjee, J. S. Muenter, and L. H. Coudert, Journal of Chemical Physics 97, 8850 (1992).

J. A. Booze and T. Baer, J. Chem. Phys. 98, 186 (1993).

Y. F. Zhu, S. L. Allman, R. C. Phillips, W. R. Garrett, and C. H. Chen, Chem. Phys. Lett. 224, 7 (1994).

V. Brenner, P. Millie, and P. Millie, Z. Phys. D 30, 327 (1994). 
S. M. Resende and W. B. De Almeida, Chem. Phys. 206, 1 (1996).

A. Karpfen, J. Phys Chem. A 103, 11431 (1999).

K. Shuler and C. E. Dykstra, J. Phys Chem. A 104, 4562 (2000).

K. Shuler and C. E. Dykstra, J. Phys Chem. A 104, 11522 (2000).

S. Hirabayashi, N. Yazawa, and Y. Hirahara, J. Phys Chem. A 107, 4829 (2003).

J. B. Klauda, S. L. Garrison, J. Jiang, G. Arora, and S. I. Sandler, J. Phys Chem. A 108, 107 (2004).

K. De Bleecker, A. Bogaerts, and W. Goedheer, Physical Review E 73, 026405 (2006).

Y.-C. Lee, V. Venkatesan, Y.-P. Lee, P. Macko, K. Didriche, and M. Herman, Chem. Phys. Lett. 435, 247 (2007).

C. C. Wang, P. Zielke, O. F. Sigurbjo“rnsson, C. Ricardo Viteri, and R. Signorell, J. Phys. Chem. A 113, 11129 (2009).

A. P. Milce, D. E. Heard, R. E. Miller, and B. J. Orr, Chem. Phys. Lett. 250, 95 (1996).

C. Lauzin, K. Didriche, P. Macko, J. Demaison, J. Liévin, and M. Herman, J. Phys Chem. A 113, 2359 (2009).

C. Lauzin, K. Didriche, J. Liévin, M. Herman, and A. Perrin, J. Chem. Phys. 130, 204306 (2009).

K. Didriche, C. Lauzin, P. Macko, M. Herman, and W. J. Lafferty, Chem. Phys. Lett. 469, 35 (2009). 
K. A. Keppler, G. C. Mellau, S. Klee, B. P. Winnewisser, M. Winnewisser, J. Plíva, and K. N. Rao, J. Mol. Spectrosc. 175, 411 (1996).

S. Robert, M. Herman, A. Fayt, A. Campargue, S. Kassi, A. Liu, L. Wang, G. Di Lonardo, and L. Fusina, Mol. Phys. 106, 2581 (2008).

D. Romanini, A. A. Kachanov, and F. Stoeckel, Chem. Phys. Lett. 270, 546 (1997).

K. W. Busch and M. A. Busch, Cavity-Ringdown Spectroscopy. (American Chemical Society, Washington, 1999).

G. Berden, R. Peeters, and G. Meijer, Int. Rev. Phys. Chem. 19, 565 (2000).

K. Didriche, C. Lauzin, P. Macko, W. J. Lafferty, R. J. Saykally, and M.

Herman, Chem. Phys. Lett. 463345 (2008).

A7 Ramos, J. Santos, L. Abad, D. Bermejo, V. J. Herrero, and I. Tanarro, J. Raman Spectrosc. 40, 1249 (2009).

M. Herman, K. Didriche, D. Hurtmans, B. Kizil, P. Macko, A. Rizopoulos, and P. Van Poucke, Mol. Phys. 105, 815 (2007).

D. Romanini, A. A. Kachanov, and F. Stoeckel, Chem. Phys. Lett. 270, 538 (1997).

P. Macko, D. Romanini, S. N. Mikhailenko, O. V. Naumenko, S. Kassi, A. Jenouvrier, V. G. Tyuterev, and A. Campargue, J. Mol. Spectrosc 227 (227), 90 (2004).

A. E. Thornley and J. M. Hutson, Chem. Phys. Lett. 198, 1 (1992). 
G. T. Fraser, F. J. Lovas, R. D. Suenram, J. Z. Gillies, and C. W. Gillies, Chem. Phys. Lett. 163, 91 (1992).

PGOPHER, a Program for Simulating Rotational Structure, C.M. Western, University of Bristol, U.K.; http://pgopher.chm.bris.ac.uk

J. Crovisier, Earth, Moon and Planets 79, 125 (1999).

T. Y. Brooke, A. T. Tokunaga, H. A. Weaver, J. Crovisier, D. BockeleeMorvan, and D. Crisp, Nature 383, 606 (1996).

M. J. Mumma, N. Dello Russo, M. A. DiSanti, K. Magee-Sauer, R. E. Novak, S. Brittain, T. Rettig, I. S. McLean, D. C. Reuter, and L.-H. Xu, Science 292, 1334 (2001).

S. T. Ridgway, Astrophys. J. 187, L41 (1974).

T. Encrenaz, H. Feuchtgruber, S. K. Atreya, B. Bezard, E. Lellouch, J. Bishop, S. Edgington, T. De Graauw, M. Griffin, and M. F. Kessler, Astron. Astrophys. 333, L43 (1998).

M. Kanakidou, B. Bonsang, J. C. Le Roulley, G. Lambert, D. Martin, and G. Sennequier, Nature 333, 51 (1988).

A. Goldman, F. J. Murcray, R. D. Blatherwick, J. R. Gillis, F. S. Bonomo, F. H. Murcray, D. G. Murcray, and R. J. Cicerone, J. Geophys. Res. 86, 12143 (1981).

A. Coustenis, R. K. Achterberg, B. J. Conrath, D. E. Jennings, A. Marten, D. Gautier, C. A. Nixon, F. M. Flasar, N. A. Teanby, B. Bezard, and e. al, Icarus 189, 35 (2007). 
J. Cernicharo, A. M. Heras, L. B. F. M. Waters, E. Gonzalez-Alfonso, S. Hony, I. Yamamura, M. Guelin, R. Neri, E. Dartois, S. Perez-Martinez, and e. al, European Space Agency, [Special Publication] SP (1999), SP-427(Universe as Seen by ISO, Vol. 1), 285 (1999).

M. Matsuura, P. R. Wood, G. C. Sloan, A. A. Zijlstra, J. T. van Loon, M. A. T.

Groenewegen, J. A. D. L. Blommaert, M.-R. L. Cioni, M. W. Feast, H. J.

Habing, S. Hony, E. Lagadec, C. Loup, J. W. Menzies, L. B. F. M. Waters, and P. A. Whitelock, Monthly Notices of the Royal Astronomical Society, 415 (2006).

J. P. Fonfria, J. Cernicharo, M. J. Richter, and J. H. Lacy, ApJ 673, 445 (2008).

J. H. Lacy, N. J. Evans, II, J. M. Achtermann, D. E. Bruce, J. F. Arens, and J. S. Carr, ApJ 342, L43 (1989).

N. J. Evans, J. H. Lacy, and J. S. Carr, Astrophys. J. 383, 674 (1991).

F. Lahuis and E. Van Dishoeck, Astron. Astrophys. 355, 699 (2000).

D. Farrah, J. Bernard-Salas, H. W. W. Spoon, B. T. Soifer, L. Armus, B.

Brandl, V. Charmandaris, V. Desai, S. Higdon, D. Devost, and e. al, ApJ 667, 149 (2007).

${ }_{69}$ P. Sonnentrucker, E. Gonzalez-Alfonso, and D. A. Neufeld, ApJ 671, L37 (2007).

R. Wehr, S. Kassi, D. Romanini, and L. Gianfrani, Appl. Phys. B 92, 459 (2008). 
${ }^{71}$ G. Durry, J. S. Li, I. Vinogradov, A. Titov, O. Joly, J. Cousin, T.

Decarpenterie, N. Amarouche, X. Liu, B. Parvitte, O. Korablev, M. Gerasimov, and V. Zéninari, Appl. Phys. B DOI 10.1007/s00340-010-3924-y (2010). 
Table 1

\begin{tabular}{|c|c|c|c|c|c|c|c|}
\hline$a$-type & \multicolumn{7}{|c|}{$b$-type } \\
\hline${ }^{q} Q(J)$ & ${ }^{p} Q_{3}(J)$ & ${ }^{p} Q_{2}(J)$ & ${ }^{p} Q_{1}(J)$ & ${ }^{r} Q_{0}(J)$ & ${ }^{r} Q_{1}(J)$ & ${ }^{r} Q_{2}(J)$ & ${ }^{r} Q_{3}(J)$ \\
\hline 6538.29 & 6541.80 & 6544.14 & 6546.51 & 6548.84 & 6551.11 & 6553.43 & 6555.70 \\
\hline
\end{tabular}

URL: http://mc.manuscriptcentral.com/tandf/tmph 
Table 2

\begin{tabular}{|l|l|l|l|}
\hline & Ground state & \multicolumn{1}{|c|}{$\mathbf{B}_{2}$ state } & \multicolumn{1}{|c|}{$\mathbf{A}_{1}$ state } \\
\hline Origin $\left(\mathrm{cm}^{-1}\right)$ & 0 & 6547.58 & 6538.32 \\
\hline $\mathrm{A}\left(\mathrm{MH}_{\mathrm{Z}}\right)$ & 35282 & 36000 & 35250 \\
\hline $\mathrm{B}\left(\mathrm{MH}_{\mathrm{Z}}\right)$ & 1913.29003 & 1900 & 1904 \\
\hline $\mathrm{C}\left(\mathrm{MH}_{\mathrm{Z}}\right)$ & 1798.60956 & 1810 & 1795 \\
\hline$\Delta_{\mathrm{JK}}\left(\mathrm{MH}_{\mathrm{Z}}\right)$ & 2.3341 & $2.3341^{*}$ & $2.3341^{*}$ \\
\hline
\end{tabular}

* Constrained to the ground state value. 
Figure 1: CW-CRDS jet-cooled spectrum of a mixture of $12 \mathrm{C} 2 \mathrm{H} 2$ and $\mathrm{Ar}$ around $6548.5 \mathrm{~cm}-1$. The initial FANTASIO set-up was used for the spectrum presented in panel (1), then updated with a second turbomolecular pump in panel (2) then with the more reflective CRDS mirror set in panel (3). The intensity scale was multiplied by a factor 1.5 in panel (3) to reflect the gain in the S/N level, compared to panel (2) (see text). The slit nozzle was $14 \times 0.03 \mathrm{~mm}(1) ; 30 \times 0.015 \mathrm{~mm}$ (2); and $10 \times 0.03 \mathrm{~mm}$ (3). The experimental conditions are $1 \% \mathrm{C} 2 \mathrm{H} 2$ in $99 \% \mathrm{Ar} ; \mathrm{p} 0 / \mathrm{p} \infty=81000 / 3.3$

$\mathrm{Pa}(1) ; 151000 / 2.1 \mathrm{~Pa}(2) ;$ and $129000 / 1.6 \mathrm{~Pa}(3)$. $254 \times 190 \mathrm{~mm}(96 \times 96 \mathrm{DPI})$ 
Figure 2: Absorption features recorded using FANTASIO+, with $12 \mathrm{C} 2 \mathrm{H} 2$ seeded in $\mathrm{Ne}$ (top) and $\mathrm{Ar}$ (middle) using adapted nozzle geometries. The spectrum of the pure acetylene dimer simulated using b-type selection rules is presented at the bottom (see text for further details). The central $\mathrm{Q}$ branches are identified according to the usual notation . Flow and pressure conditions: $\mathrm{C} 2 \mathrm{H} 2 / \mathrm{Ne}$ $184 / 1118 \mathrm{sccm} / \mathrm{min}, \mathrm{p} 0 / \mathrm{p}_{\infty}=322000 / 0.5 \mathrm{~Pa}$, axisymmetric nozzle, $150 \mu \mathrm{m}$ diameter (top); $\mathrm{C} 2 \mathrm{H} 2 / \operatorname{Ar} 185 / 2929 \mathrm{sccm} / \mathrm{min}, \mathrm{p} 0 / \mathrm{p}_{\infty}=126000 / 2.5 \mathrm{~Pa}$, slit nozzle $10 \times 0.03 \mathrm{~mm}$ (middle). Trot $=$ $20 \mathrm{~K}$ in the simulation. $254 \times 190 \mathrm{~mm}(96 \times 96 \mathrm{DPI})$ 
Figure 3: Portion around $6548 \mathrm{~cm}-1$ of the CW-CRDS jet-cooled spectrum of a mixture of $12 \mathrm{C} 2 \mathrm{H} 2$ and $\mathrm{Ar}$ recorded using the same injection flow rate of $\mathrm{Ar}$ and acetylene flow rates increasing in the ratio 1 (bottom), 2 (middle) and 3 (top). The initial FANTASIO spectrometer was used with, however two turbomolecular pumping units. The slit nozzle was $30 \times 0.015 \mathrm{~mm}$. Flow and pressure conditions: $\mathrm{C} 2 \mathrm{H} 2 / \mathrm{Ar} 98.4 / 4882 \mathrm{sccm} / \mathrm{min}, \mathrm{p} 0 / \mathrm{p}_{\infty}=146000 / 1.9 \mathrm{~Pa}$ (bottom); $\mathrm{C} 2 \mathrm{H} 2 / \operatorname{Ar} 196.8 / 4882$ $\mathrm{sccm} / \mathrm{min}, \mathrm{p} 0 / \mathrm{p}_{\infty}=147000 / 1.6 \mathrm{~Pa}$ (middle); $\mathrm{C} 2 \mathrm{H} 2 / \operatorname{Ar} 290 / 4882 \mathrm{sccm} / \mathrm{min}, \mathrm{p} 0 / \mathrm{p} \infty=149000 / 1.9$ $\mathrm{Pa}$ (top).

$254 \times 190 \mathrm{~mm}(96 \times 96 \mathrm{DPI})$ 


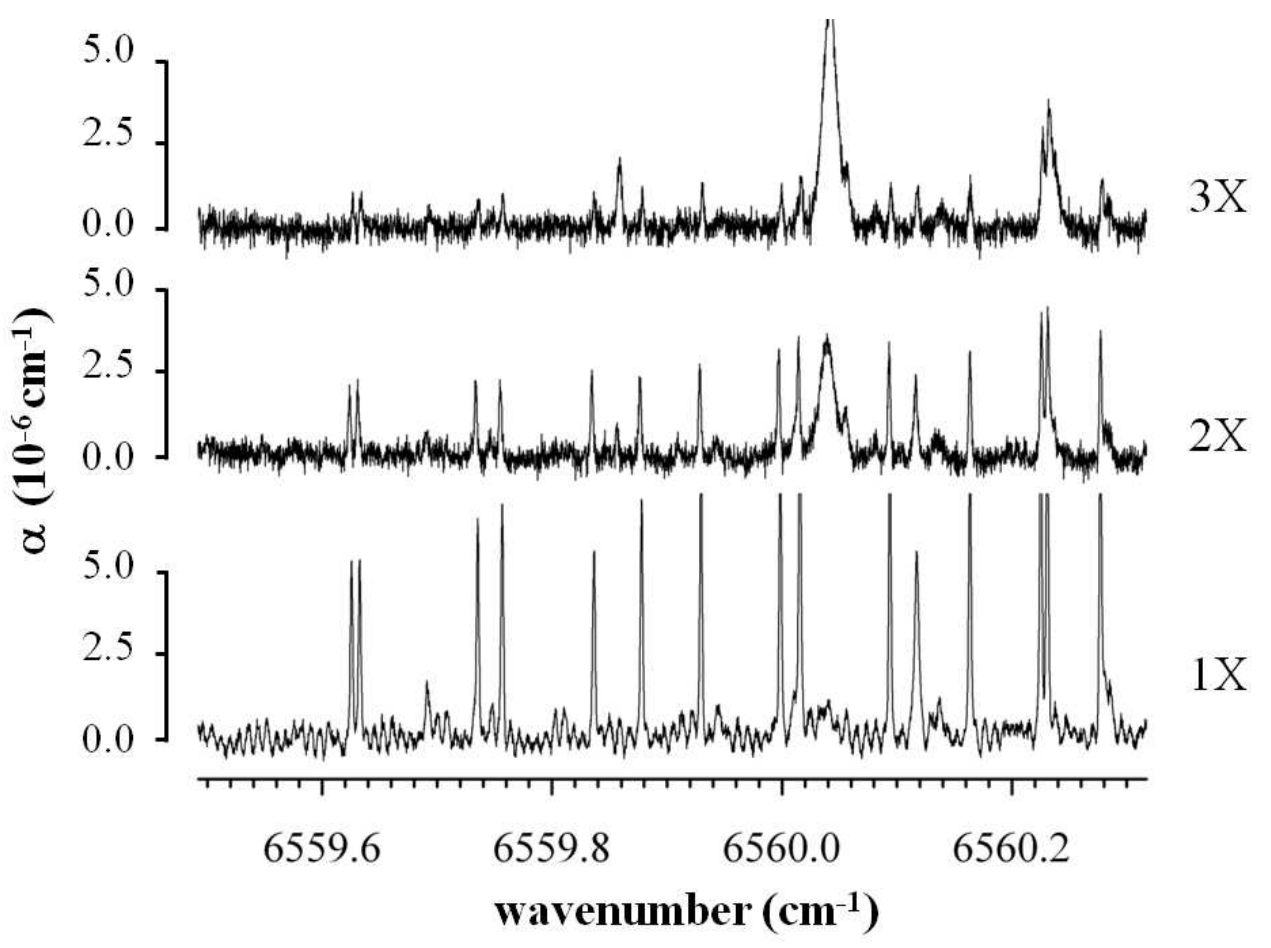

Figure 4: Portion around $6560 \mathrm{~cm}-1$ of the CW-CRDS jet-cooled spectrum of a mixture of $12 \mathrm{C} 2 \mathrm{H} 2$ and $\mathrm{Ar}$ recorded using the same injection flow rate of $\mathrm{Ar}$ and acetylene flow rates increasing in the ratio 1 (bottom), 2 (middle) and 3 (top). The initial FANTASIO spectrometer was used with, however the two turbomolecular pumping units. The slit nozzle was $30 \times 0.015 \mathrm{~mm}$. Flow and pressure conditions: $\mathrm{C} 2 \mathrm{H} 2 / \mathrm{Ar} 98.4 / 4882 \mathrm{sccm} / \mathrm{min}, \mathrm{pO} / \mathrm{p}_{\infty}=146000 / 1.9 \mathrm{~Pa}$ (bottom); $\mathrm{C} 2 \mathrm{H} 2 / \mathrm{Ar}$ $196.8 / 4882 \mathrm{sccm} / \mathrm{min}, \mathrm{p} 0 / \mathrm{p}_{\infty}=147000 / 1.6 \mathrm{~Pa}$ (middle); $\mathrm{C} 2 \mathrm{H} 2 / \mathrm{Ar} 290 / 4882 \mathrm{sccm} / \mathrm{min}, \mathrm{p} 0 / \mathrm{p}_{\infty}=$ $149000 / 1.9 \mathrm{~Pa}$ (top). $254 \times 190 \mathrm{~mm}(96 \times 96 \mathrm{DPI})$ 
Figure 5: Bottom: CW-CRDS jet-cooled spectrum of a mixture of $12 \mathrm{C} 2 \mathrm{H} 2$ and Ar recorded using FANTASIO+. Top: Spectrum of the pure acetylene dimer simulated using a-type selection rules. Middle: Spectrum of the pure acetylene dimer simulated using a- and also b-type selection rules; The b-type sub-bands with $\mathrm{K}^{\prime \prime}=3$ to 5 are included. The branches are identified according to the usual notation. Flow and pressure conditions are identical to those of Figure 2 (mid panel). Trot $=$ $20 \mathrm{~K}$ in the simulations.

$254 \times 190 \mathrm{~mm}(96 \times 96 \mathrm{DPI})$ 
Figure 6: T-shaped structure of the pure acetylene dimer, with principal axes of inertia. $254 \times 190 \mathrm{~mm}(96 \times 96 \mathrm{DPI})$ 